\title{
Magnitude and Determinants of Dropout from Community-Based Health Insurance Among Households in Manna District, Jimma Zone, Southwest Ethiopia
}

This article was published in the following Dove Press journal:

ClinicoEconomics and Outcomes Research

\author{
Wakuma Akafu Eseta (D) \\ Teferi Daba Lemma (D) ${ }^{2}$ \\ Edosa Tesfaye Geta $\mathbb{D}^{3}$ \\ 'Ghimbi District Health Office, Ghimbi, \\ Oromia, Ethiopia; ${ }^{2}$ Department of Health \\ Policy and Management, Faculty of Public \\ Health, Institute of Health, Jimma \\ University, Jimma, Oromia, Ethiopia; \\ ${ }^{3}$ School of Public Health, Institute of \\ Health, Wollega University, Nekemte, \\ Oromia, Ethiopia
}

Background: Community-based health insurance (CBHI) is a prepayment method of financial contributions for healthcare which aims to risk pooling, avoidance of catastrophic and impoverishing health expenditure. However, a high dropout from the scheme remains the biggest challenge to effective and sustainable progress towards universal financial protection in low- and middle-income countries. While large literature had examined initial enrollment and factors associated with it, only a few studies dealt with dropout. So the study aimed to assess the magnitude and determinants of dropout from community-based health insurance among households in Manna district, Jimma zone, Oromia Regional State, Ethiopia.

Methods: A community-based cross-sectional study design was employed to collect data from 634 household heads from March 1 to 30, 2020. A multistage sampling technique was carried out and interviewer-administered questionnaires were used to collect data. Descriptive statistics and multivariable logistic regression analyses were performed, and variables with a $P$-value $<0.05$ were considered as having a statistically significant association with the dropout from the CBHI.

Results: Magnitude of dropout from CBHI was $31.9 \%$ with $95 \%$ confidence interval (CI) $=28.2-35.8 \%$ and relatively older age [adjusted odds ratio $(\mathrm{AOR})(95 \% \mathrm{CI})=0.26(0.10-$ $0.78)$, educational level [AOR $(95 \% \mathrm{CI})=0.16(0.06-0.41)]$, family size [AOR $(95 \% \mathrm{CI})$ $=0.36(0.19-0.66)]$, poor perceived quality of service $[\mathrm{AOR}(95 \% \mathrm{CI})=5.7(2.8-11.8)]$, trust in health facility $[\mathrm{AOR}(95 \% \mathrm{CI})=0.43(0.3-0.61)]$, trust in the scheme $[\mathrm{AOR}(95 \% \mathrm{CI})=0.61$ $(0.45-0.84)$ ], providers' attitude [AOR $(95 \% \mathrm{CI})=10(4.0-25.4)]$, and benefit package [AOR $(95 \% \mathrm{CI})=4.9(2.4-9.9)]$ were statistically significant determinants associated with dropout. Conclusion: Dropout from CBHI in this study area was high. Household heads' age, educational level, family size, perceived quality of service, providers' attitude, a benefits package, trust in the contracted health facility, and the scheme were the significant predictors of dropout. We strongly recommend that greater efforts should be made toward the providers' attitude, promised benefit package, and quality of services.

Keywords: dropout, health insurance, determinants, Manna, Ethiopia

\section{Background}

Community-based health insurance (CBHI) is one of the healthcare financing methods and is defined as the reduction or elimination of uncertain risk of loss for individual or household by combining a large number of similarly exposed individuals or households. ${ }^{1}$
Correspondence: Edosa Tesfaye Geta

Nekemte 395, Ethiopia

Tel +251987055188

Email edotesfa@yahoo.com 
Globally different countries are trying to provide financial protection from the costs of using health services for all individuals. While no country fully achieves this, each seeks to make progress on including funding health services in a way that protects people from the financial crisis. $^{2}$

Earlier on cost recovery for healthcare via a user charge was established in many developing countries, usually as a response to severe scarcity on government finance. However, most studies alert decision-makers to the negative effects of user fees on the demand for care, especially for that of the poorest households. ${ }^{3}$

The World health assembly introduced a prepayment financial contributions method for healthcare with the aims of risk pooling, avoidance of catastrophic and impoverishing health expenditure of individuals attributed to seeking healthcare for which CBHI was introduced which enhances resource mobilization to improve health service utilization, quality-of-life, and decrease out-of-pocket payment (OOP). ${ }^{4}$

Despite this, members are highly dropping from the scheme and membership in most CBHIs is voluntary, and members are required to renew their membership periodically. Dropping out is the failure of members to renew their insurance, which can be astonishingly high, reaching $70-80 \%$ in some cases. ${ }^{5,6}$

A continuous increase in dropout would be a death knell for the viability of any scheme because decreasing the risk pool would squeeze resource mobilization and end up with financial losses. ${ }^{7}$ The difficulty of enrolling and retaining membership for the less endowed is seen as a reason why schemes in low-income and middle-income countries (LMICs) often fail to secure satisfactorily enrolment levels. ${ }^{8}$

Individuals at low risk of falling ill dropout of the scheme, leaving only the high-risk individuals, which leads to the collapse of the CBHI schemes and compromises its sustainability. ${ }^{9}$ Low enrollment or high dropout, and the presence of too few people in the scheme is endangering the sustainable progress of this reform in many countries including sub-Saharan African countries (SSA). ${ }^{6,10}$

Ethiopia is one of the least developed countries, with $29.6 \%$ of its population living below the poverty line. ${ }^{11,12}$ Major sources of financing for the health sector in the country are from the rest of the world and households, which account for $35 \%$ and $31 \%$, respectively. ${ }^{13}$ These in turn risks the households to catastrophic health expenditure and affect healthcare access and utilization negatively. ${ }^{2,14}$

Ethiopia introduced a range of healthcare financing reforms like revenue retention and utilization, the establishment of a private wing in public hospitals, systematizing a fee waiver system and standardizing the package of exempted services; and introducing and expanding health insurance aimed at increasing the availability of resources for health as well as protecting the population from prohibitive user fees or catastrophic spending at the time of sickness. ${ }^{15}$

Evaluation of the CBHI program in Ethiopia showed that the risk of being impoverished by OOP health expenditure was $7 \%$ for CBHI members and $19 \%$ for nonmembers at the $15 \%$ threshold of non-food expenditure, ${ }^{16}$ and the per capita health service utilization rate of CBHI members was 0.7 visits/person as compared to the overall outpatient department utilization rate of the country which was 0.3 visits/capita. ${ }^{17}$

To address the issues of high OOP spending for health services, financial barriers to care and achieve UHC, Ethiopia has piloted and is scaling up CBHI for citizens in the agricultural and informal sectors, estimated to be $85 \%$ of the country's population. ${ }^{15}$

CBHI aimed to cover $80 \%$ of districts enrolling at least $80 \%$ of eligible households by 2020 in Ethiopia. ${ }^{18}$ But, nationally the overall enrolment was $48 \%$ and $36 \%$ in 2013 and 2017, respectively. ${ }^{16,19}$

In Ethiopia, while a number of studies have examined initial enrollment and factors associated with it, only a few studies have dealt with the dropout and suggest that the quality of care on offer, health status, affordability, and understanding of $\mathrm{CBHI}$ were the main factors that contributed to dropout from CBHI. ${ }^{20,21}$

Manna district is one of the four districts where a yearly based prepayment method of CBHI was first introduced and a model district by implementing CBHI in the Jimma zone. The district health office reports showed many of the CBHI scheme members are not renewing their membership. Thus, information on dropout status and what motivates enrolled people to discontinue their membership is very scarce in the study area and country.

Therefore, this study aimed to determine the magnitude and identify determinants of dropout from CBHI among households of Manna district, Jimma zone, Oromia Regional State, South West, Ethiopia.

\section{Methods and Materials}

\section{Study Setting and Period}

The study was conducted in Manna district and the data was collected from March 1-30, 2020. The district is one 
of the 21 districts in Jimma Zone which is located southwest of Ethiopia at 382 kilometers away from Addis Ababa, the capital city of the country. It is located at an altitude of about 1450 meters above sea level and generally characterized by a warm climate and the main cash crops of the area are chat and coffee, and the total population of the district was estimated to be 20,5497 and it had seven health centers and 26 health posts.

\section{Study Design and Population}

A community-based cross-sectional study design was employed. All households who were ever registered to the CBHI scheme at Manna district were the source population, whereas all households who were registered to the CBHI scheme and found in selected villages of the district with full filling inclusion criteria were the study population and included in the study.

\section{Sample Size Determination and Sampling Procedure}

The sample size was determined by using a single population proportion formula considering the following assumptions; ${ }^{22}$ $n=\frac{P_{0}\left(1-P_{0}\right)\left(\frac{Z \alpha}{2}\right)^{2} * D}{d^{2}}$, where: $n=$ sample size, $Z_{\alpha} / 2=$ standard score for $95 \%$ confidence level (1.96), $P_{0}=50 \%$ proportion of dropout was taken since there was no study found conducted in Ethiopia that addressed the objective of this study, $d=5 \%$ margin of error, $D=$ a design effect of 1.5 and, adding a $10 \%$ non-response rate, the final sample size was determined to be 634 .

Manna district was chosen purposively because it was the only district in Jimma Zone which has implemented CBHI for more than 8 years, which helps the investigators to assess the long-term determinants of dropout from CBHI.

A multistage sampling technique was employed to select kebeles (villages). Firstly, the 26 kebeles of the district were stratified into urban and rural. One urban kebele was selected purposively and eight out of 25 rural kebeles were selected by a simple random sampling technique. Then the calculated sample size was proportionally allocated to each of the kebeles based on their number of enrolled households (Figure 1).

Finally, study participants were selected using a computer-generated simple random sampling technique. The lists of household heads that were registered to CBHI were taken from the district CBHI scheme. Their usual place of residence was identified in collaboration with kebeles' leaders and the head of one-to-five networks.

\section{Data Collection Tool and Technique}

An interviewer-administered structured questionnaire that was adapted from related literature to collect relevant information. The questionnaire had five parts (socio-economic and demographic characteristics, $\mathrm{CBHI}$ information, individual/household-related factors, CBHI related factors and health service use related factors). The questionnaire was translated to the local language Afan Oromo by language experts and translated back to English by another person to ensure its consistency and finally pre-tested before the actual data collection. The internal consistency of items for independent variables with a five-point Likert scale was checked by Cronbach's alpha.

Data was collected by six diploma nurses using the pre-tested structured questionnaire through face-to-face interviews. Two supervisors who were qualified with BSc in public health were recruited. The data collectors and supervisors were trained on the data collection tool, approach to the interviews, details of interviewing techniques, respect, and maintaining the privacy and confidentiality of the respondents.

\section{Study Variables}

Dropout from CBHI was a dependent study variable, whereas socio-economic and demographic factors including (household head's age, sex, occupation, educational status, marital status, household size and wealth index), individual/ household related factors (understanding of CBHI, attitude towards CBHI, presence of chronic disease, recent illness episode, self-rated health status and perceived quality of service, trust in a health facility and trust in the CBHI scheme), health service use related factors (accessibility of service, availability of service, waiting time, providers' attitude and utilization of health service), and the CBHI related factors (affordability, benefits package, the convenience of premium collection period and scheme experience) were independent study variables (Figure 2).

\section{Operational Definition Dropout from CBHI}

Households who used to have CBHI but were not enrolled at the time of the survey were classified as drop out (coded as $1=$ dropped out and $0=$ renewed).

\section{Renew}

Households who had CBHI for more than 1 year and who were still enrolled at the time of the survey and households that were enrolled in the first year of operation, 


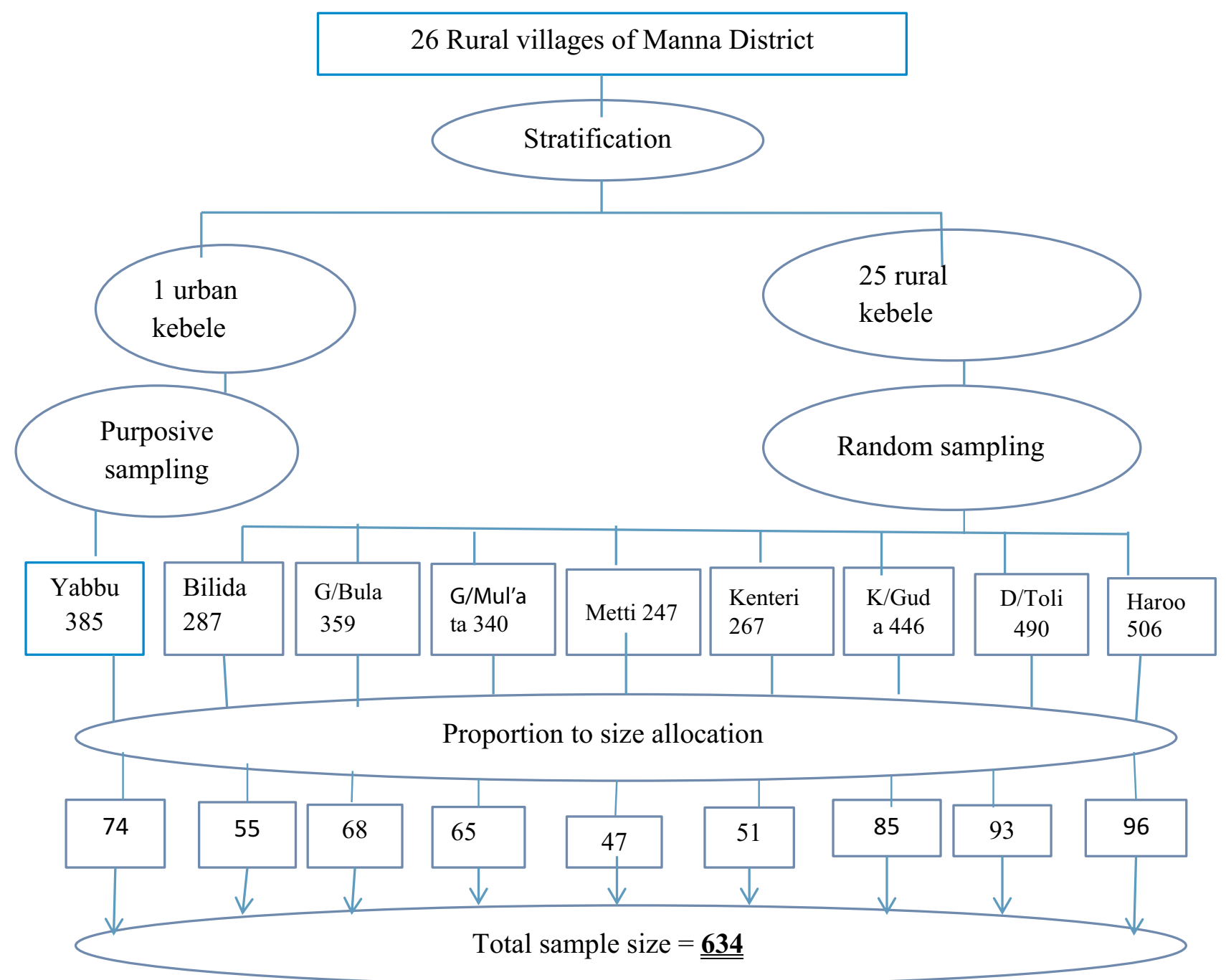

Figure I Schematic presentation of the sampling technique among households in Manna district, Jimma zone, Oromia Regional State, Southwest Ethiopia, 2020.

dropped in the second year of operation, and enrolled again in the third year of operation were considered as "renewal".

\section{Understanding of $\mathrm{CBHI}$}

Households were asked ten sets of items about CBHI, then respondents were classified as having a high level of understanding if the household answered $\geq$ mean, and a low level of understanding if the household answered $<$ mean.

\section{Scheme Experience}

Composite variables were constructed using seven items measuring the satisfaction of the respondent on the CBHI experience and design feature of the schemes with a 5-point Likert scale from strongly disagree to strongly agree, then the factor score was computed using principal components analysis (PCA).

\section{Perceived Quality of Health Service}

This was measured on a 5-point Likert scale from very poor to very good. Later, the data were regrouped into poor, medium, and good categories.

\section{Attitude Towards CBHI Scheme}

Participants were asked a set of question contains 10 items, which were measured by a 5-point Likert scale from strongly agree to strongly disagree. The assumption of summated scales was employed to examine the overall score, which represents the respondent's position on the continuum of favorableness towards CBHI. ${ }^{22}$ Accordingly, 10 items have a potential minimum sum score of 10 to a maximum sum score of 50 . When the total score of each individual is close to 50 it shows the most favorable 


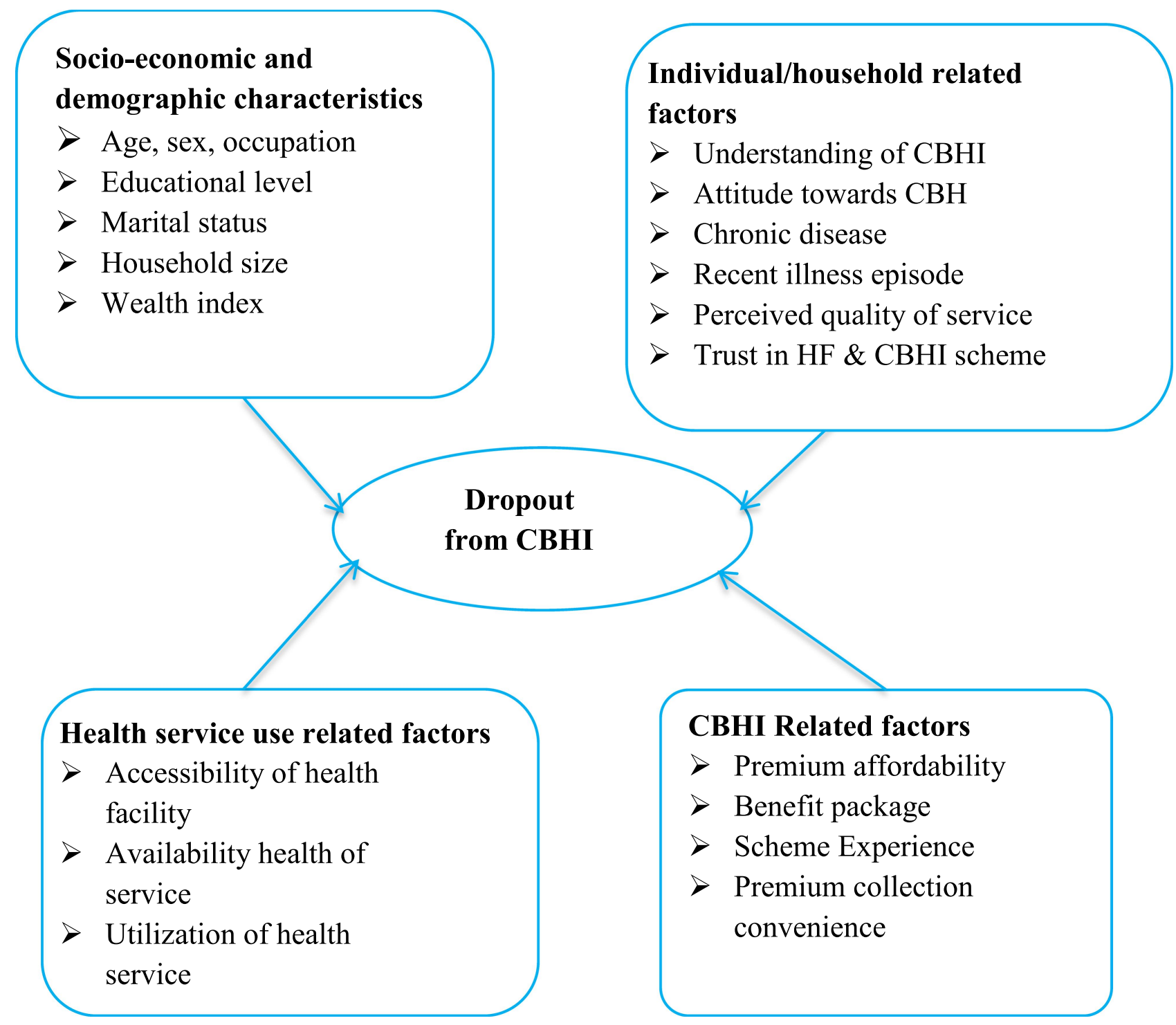

Figure 2 Conceptual framework for determinants of dropout from community-based health insurance.

attitude and when the score is close to 10 it shows the most unfavorable attitude towards the scheme. Thus, based on this continuum of favorableness it was categorized into unfavorable attitude, which scored between 10 and 29; neutral attitude, which scored 30; and favorable attitude, which scored 31-50.

\section{Household Wealth Index}

Households assets data was collected based on the kinds of consumer goods they own, then factor scores were derived using PCA, and then the composite scores were categorized into five quantiles. The first $20 \%$ quantile was classified as the poorest, whereas the last $20 \%$ quantile was considered as the richest.

\section{Health Service Utilization}

This item was asked as "Did this household member encounter any acute illness, accident or injury during the past 12 months and seek medical treatment for the past 12 months?" If "Yes, 1" and "Otherwise, 0".

Trust in Healthcare Facilities

Participants were asked ten items with a 5-point Likert scale from strongly disagree to strongly agree, then the factor score was computed using PCA and the score was used as a continuous variable during the analysis.

\section{Trust in CBHI Scheme}

Participants were asked five items with a 5-point Likert scale from strongly disagree to strongly agree, then the 
factor score was computed using PCA and used as a continuous variable during the analysis.

\section{Provider's Attitude}

Participants were asked ten items of questions with a 5-point Likert scale from strongly disagree to strongly agree. Factor score was computed using PCA and extracted factor scores were ranked based on percentile then categorized into unfavorable, neutral, or favorable attitude towards CBHI member.

\section{Capacity to Afford}

Participants were asked using a 5-point Likert scale from strongly disagree to strongly agree. Factor score was computed using PCA and extracted factor scores were ranked based on percentile then categorized into low, medium, and high level affordability.

\section{Data Management and Analysis}

After checking the completeness and consistency of the data, the data were entered to Epi data version 3.1 and then exported to SPSS version 26 for analysis.

Descriptive analyses were used to describe drop-out status and presented in terms of frequencies, percentages, tables, and graphs as necessary. Simple binary logistic regression analysis was performed to select candidate variables for multivariable analysis. Then, variables with a $P$-value $<0.25$ in the simple binary logistic regression analysis were taken as candidates for multivariable analysis.

Finally, multivariable logistic regression analysis was performed to control for the possible confounding effect of the selected variables and variables with a $P$-value $<0.05$ were taken as statistically significant association with dropout from $\mathrm{CBHI}$ and $\mathrm{AOR}$ with a 95\% confidence interval (CI) was used to show the degree of association between the independents and outcome variables.

Necessary assumption and prerequisite for Principal Components Analysis (PCA) was checked. Multi-collinearity between independent variables was checked using the variance inflation factor (VIF) and the maximum VIF was found to be 1.52. For a finally fitted multivariable logistic regression model, model fitness was checked by Hosmer-Lemeshow goodness-of-fit and the $P$-value was found to be 0.744 .

\section{Ethical Consideration}

The ethical clearance was obtained from the ethical review committee of Jimma University, Institute of Health Science (reference number: IRB00052/2020). The necessary permission was obtained from the Manna district health and administrative offices after a formal letter was written from Jimma zonal health department to the district. This study was conducted in accordance with the Declaration of Helsinki. All study participants were well informed about the purpose of the study and informed written consent was secured from the study participants prior to the interview. The study participants' confidentiality was maintained and no personal identifiers were used in the data collection tools and codes were used in place of it. All paper-based and computer-based data were kept in protected and safe locations. The recorded data were not accessed by a third person, except the research team, and data sharing will be enacted based on the ethical and legal rules of data sharing.

\section{Results}

\section{Socio-Demographic and Economic Characteristics of Households}

A total of 617 household heads participated in the study, making a response rate of $97.3 \%$. The mean age of the respondents was $44.71 \pm 11.2$ years and the majority of the respondents $(544 ; 88.2 \%)$ were from rural areas, and 522 $(84.6 \%)$ were males. The majority of the respondents were Oromo in ethnicity, which accounted for 528 (85.6\%), and Muslims constituted 509 (82.5\%) of participants. Regarding the educational status of respondents, more than half of them $(313 ; 50.7 \%)$ had no formal education and $451(73 \%)$ of them were farmers. The mean family size of the participants was $5.54 \pm 1.87$, and 432 (70\%) of the respondents walked $\geq 30$ minutes to visit the nearest health facilities (Table 1).

\section{Community-Based Health Insurance Status of Households}

Among the study participants, 541 (87.7\%) households were payers and $76(12.3 \%)$ of respondents were indigents who were exempted from contributing to CBHI. Almost all of them $(607 ; 98.4 \%)$ had CBHI identification cards. Of those who renewed their membership, only 137 (32.6\%) were renewing consistently over the past 5 years.

Among households who discontinued their membership, $103(52.3 \%)$ of them had one year and seven $(3.5 \%)$ had 4 years of stay in the scheme. About 80 $(19 \%)$ and $31(16 \%)$ of those who had renewed and dropped from $\mathrm{CBHI}$, respectively, had no intention to renew their membership in the next coming year. 
Table I Socio-Demographic and Economic Characteristics Among Households in Manna District CBHI Members, Jimma Zone, Oromia Regional State, Southwest Ethiopia, 2020

\begin{tabular}{|c|c|c|c|c|}
\hline \multirow[t]{2}{*}{ Variables } & \multirow[t]{2}{*}{ Category } & \multicolumn{2}{|l|}{ CBHI Status } & \multirow{2}{*}{$\begin{array}{l}\text { Total, } \\
\text { N (\%) }\end{array}$} \\
\hline & & Renewed, N (\%) & Dropped, N (\%) & \\
\hline \multirow[t]{4}{*}{ Age in years } & $18-30$ & $37(8.8)$ & $25(12.7)$ & $62(10)$ \\
\hline & $31-40$ & $|3|(3 \mid .2)$ & $74(37.6)$ & $205(33.2)$ \\
\hline & $40-50$ & $133(3 \mid .7)$ & $64(32.5)$ & $197(31.9)$ \\
\hline & $\geq 51$ & $119(28.3)$ & $34(17.3)$ & $153(24.8)$ \\
\hline \multirow[t]{2}{*}{ Residence } & Rural & 371 (88.3) & $173(87.8)$ & $544(88.2)$ \\
\hline & Urban & 49 (II.7) & $24(12.2)$ & $73(11.8)$ \\
\hline \multirow[t]{2}{*}{ Sex } & Male & $370(88.1)$ & $152(77.2)$ & $522(84.6)$ \\
\hline & Female & $50(11.9)$ & $45(22.8)$ & $95(15.4)$ \\
\hline \multirow[t]{4}{*}{ Ethnic group } & Oromo & $371(88.3)$ & 157 (79.9) & $528(85.6)$ \\
\hline & Amhara & $6(1.4)$ & $7(3.6)$ & $13(2.1)$ \\
\hline & Dawuro & $25(6)$ & $19(9.6)$ & $44(7.1)$ \\
\hline & Other & $18(4.3)$ & $14(7.1)$ & $32(5.2)$ \\
\hline \multirow[t]{3}{*}{ Religion } & Muslim & $365(86.9)$ & $144(73.1)$ & $509(82.5)$ \\
\hline & Orthodox & $35(8.3)$ & $38(19.3)$ & $35(5.7)$ \\
\hline & Protestant & $20(4.8)$ & $15(7.6)$ & $73(11.8)$ \\
\hline \multirow[t]{4}{*}{ Marital status } & Married & 385 (91.7) & $168(85.3)$ & $553(89.6)$ \\
\hline & Divorced & $13(3.1)$ & $15(7.6)$ & $28(4.5)$ \\
\hline & Separated & $9(2.1)$ & $9(4.6)$ & $18(2.9)$ \\
\hline & Widowed & $13(3.1)$ & $5(2.5)$ & $18(2.9)$ \\
\hline \multirow[t]{4}{*}{ Educational level } & Unable to read and write & $105(25)$ & $94(47.7)$ & $199(32.3)$ \\
\hline & Able to read and write & $74(17.6)$ & $40(20.3)$ & $114(18.5)$ \\
\hline & Primary education & $135(32.1)$ & $46(23.4)$ & I8I (29.3) \\
\hline & Secondary and above & $106(25.2)$ & $17(8.6)$ & $123(19.9)$ \\
\hline \multirow[t]{4}{*}{ Household occupation } & Farmer & $317(75.5)$ & $134(68)$ & $451(73.1)$ \\
\hline & Merchant & $36(8.6)$ & $16(8.1)$ & $52(8.4)$ \\
\hline & Daily laborer & $45(10.7)$ & $29(14.7)$ & $74(12)$ \\
\hline & Petty trader and other & $22(5.2)$ & $18(9.1)$ & $40(6.5)$ \\
\hline \multirow[t]{2}{*}{ Household size } & $\leq 5$ & $175(4 \mid .7)$ & $12(64)$ & $301(48.8)$ \\
\hline & $>5$ & $245(58.3)$ & $71(36)$ & $316(51.2)$ \\
\hline \multirow[t]{2}{*}{ Distance from health facility (in minutes) } & $<30$ & $137(32.6)$ & $48(24.4)$ & $185(30)$ \\
\hline & $\geq 30$ & $283(67.4)$ & $149(75.6)$ & $432(70)$ \\
\hline \multirow[t]{2}{*}{ Presence of elderly people (age $\geq 60$ ) } & No & $328(78.1)$ & $173(87.8)$ & $50 I(8 I .2)$ \\
\hline & Yes & $92(21.9)$ & $24(12.2)$ & $116(18.8)$ \\
\hline \multirow[t]{2}{*}{ Presence of children in household (age $\geq 18$ ) } & No & $158(37.6)$ & $93(47.2)$ & $251(40.7)$ \\
\hline & Yes & $262(62.4)$ & $104(52.8)$ & $366(59.3)$ \\
\hline \multirow[t]{2}{*}{ Under five children in the household } & No & $214(5 \mathrm{I})$ & $116(58.9)$ & $330(53.5)$ \\
\hline & Yes & $206(49)$ & $8 I(4 I .1)$ & $287(46.5)$ \\
\hline \multirow[t]{5}{*}{ Wealth index } & Poorest & $73(17.4)$ & $48(24.4)$ & $121(19.6)$ \\
\hline & Poor & $83(19.8)$ & $4 \mathrm{I}(20.8)$ & $124(20.1)$ \\
\hline & Middle & $92(21.9)$ & $33(16.8)$ & $125(20.3)$ \\
\hline & Rich & $85(20.2)$ & $38(19.3)$ & $123(19.9)$ \\
\hline & Richest & $87(20.7)$ & $37(18.8)$ & $124(20.1)$ \\
\hline
\end{tabular}


Concerning the source of information for CBHI, about $420(68.1 \%)$ obtained from officials in public meetings followed by health professionals in health facilities which accounted for 329 (53.3\%). The main reasons of households for being a member at the beginning were to finance healthcare expense at once; $312(50.6 \%)$ followed by children in the household need healthcare services (304; 49.4\%)

\section{Magnitude and Reasons of Dropout from Community-Based Health Insurance}

The magnitude of dropout from CBHI among household in Manna district after 5 years of operation was found to be 197 (31.9\%), 95\% CI=28.2-35.8\% (Figure 3).

The households who did not renew their membership of CBHI reasoned out different reasons for their discontinuation of their membership (Figure 4), such as the registration and premium fee was not affordable for 56 (28.4\%), followed by the quality of health service provided to them was poor for $46(23.4 \%)$.

Among households who had renewed their membership $(420 ; 68.1 \%)$, the best single reasons for renewing their membership were; the premium was low compared to user fee $(151 ; 36 \%)$ followed by children in their households needed healthcare services (109; 26\%) (Figure 5).

\section{Determinants of Dropout from Community-Based Health Insurance}

The study identified the significant determinants of dropout from CBHI membership using multivariable logistic regression analysis (Table 2).

Accordingly, the household head's age had a significant association with dropout from CBHI that showed odds of

\section{CBHI status}

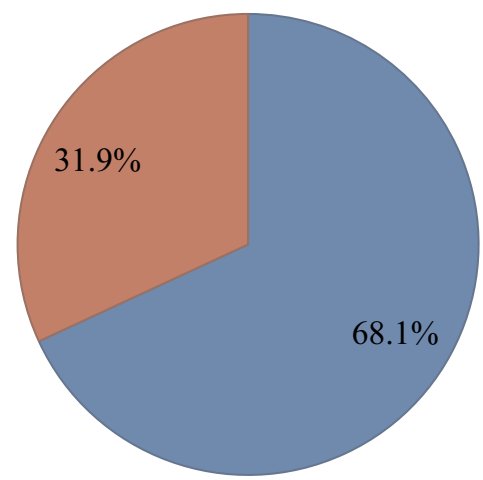

Renewed

Dropped

Figure 3 Community based health insurance status among household in Manna district, Jimma zone, Oromia Regional State, Southwest Ethiopia, 2020. dropout from CBHI decreased by $74 \%$ among household heads having the age groups $\geq 51$ years as compared to household heads having age groups 18-30 years [AOR $(95 \% \mathrm{CI})=0.26(0.1-0.78)]$.

Concerning the educational level of households heads, the households whose educational level was primary and secondary, and above educational were 68\% [AOR (95\% $\mathrm{CI})=0.32(90.16-0.66)]$ and $86 \%[\mathrm{AOR}(95 \% \mathrm{CI})=0.16$ (0.06-0.41)], respectively, less likely to dropout from $\mathrm{CBHI}$ as compared to those who were unable to read and write.

The households who discontinued their membership, the main reason they provided for their dropout from CBHI was unaffordability of registration and premium fee $(56 ; 28.43 \%)$. Again, those who were on the highest quantile wealth index seem less likely to dropout from CBHI as compared to the poorest quantiles. However, there was no statistically significant difference between those who had renewed and dropped from CBHI in each quantile of wealth index and among different level of ability to afford CBHI.

This study also revealed that households' family size was significantly associated with dropout from CBHI. Accordingly, the households who had $>5$ family members were $64 \%$ less likely to dropout from $\mathrm{CBHI}$ as compared to those who had $\leq 5$ family members [AOR $(95 \% \mathrm{CI})$ $=0.36(0.19-0.66)]$.

Regarding the understanding and attitude towards CBHI, there was no statistically significant difference among respondents who had renewed and dropped out from CBHI. Surprisingly, there was a high level of understanding of $\mathrm{CBHI}$ and favorable attitude towards CBHI scheme, irrespective of the individual membership status.

This study showed that perceived quality of service determines dropout from CBHI scheme. The likelihood of dropout from the scheme among households who had a poor perceived quality of service was almost 6-times higher as compared to their counterparts [AOR $(95 \% \mathrm{CI})$ $=5.7(2.8-11.8)]$.

The trust in contracted health facilities and $\mathrm{CBHI}$ scheme had an association with dropout from CBHI. Accordingly, for a one unit increase of trust score in public healthcare facilities the odds of dropout from CBHI was decreased by $57 \%$ [AOR $(95 \% \mathrm{CI})=0.43(0.3-0.61)]$. In addition, for a one unit increase of trust score in CBHI scheme the odds of dropout from CBHI decreased by $39 \%$ [AOR $(95 \% \mathrm{CI})=0.61(0.45-0.84)]$. 


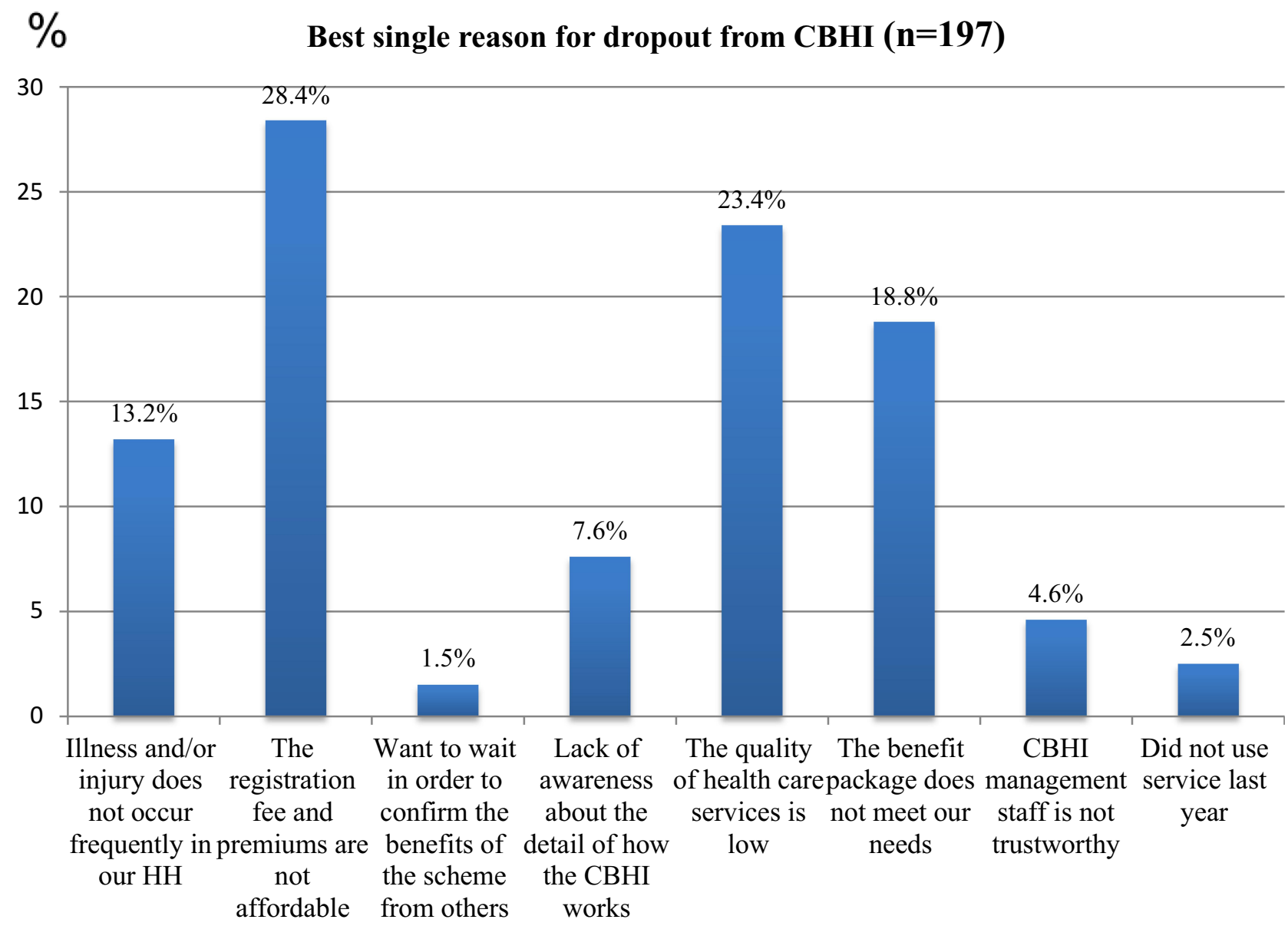

Figure 4 Best single reason for dropout from CBHI among household in Manna district, Jimma zone, Oromia Regional State, Southwest Ethiopia, 2020.

The provider's attitude towards CBHI members also had a greater impact to retain membership. This study showed that the odds of dropout from CBHI was 10- and 4-times higher among households who perceived an unfavorable and neutral provider's attitude towards CBHI member $[$ AOR $(95 \% \mathrm{CI})=10(4-25.4)$ and AOR $(95 \%$ $C I)=4.0$ (1.5-9.99), respectively], as compared to who perceived a favorable provider's attitude.

Regarding benefit package, the odds of dropout from CBHI were 4.9- and 4-times higher among subjects who disagreed and were neutral to the received promised benefit package as compared to subjects who agreed on the received promised benefit package during the period of membership [AOR $(95 \% \mathrm{CI})=4.9(2.4-9.9)$ and AOR $(95 \% \mathrm{CI})=4(1.5-9.99)$, respectively].

\section{Discussion}

In provision and utilization of health services, $\mathrm{CBHI}$ plays a great role in reducing out-of-pocket expenditure, increasing access to the service, reducing the risk of extreme poverty, improving cost recovery, and increasing the progress towards UHC. ${ }^{23}$ However, dropout of members from the scheme is becoming a serious problem. Thus, this study has attempted to assess the magnitude and determinants of dropout from the CBHI scheme.

The study determined the magnitude of dropout from CBHI, which was $31.9 \%$, almost in line with study findings conducted in Burkina Faso $(30.9 \%)^{24}$ and Ghana $(34.8 \%){ }^{25}$ This could be due to the fact that the sample size of the study was almost similar, 553 in Burkina Faso and 600 in Ghana. In addition, this study and the study in Ghana assess dropout over 5 years of operation of the scheme.

However, the magnitude of dropout from the scheme was higher than the magnitude of dropout in Vietnam $(21.1 \%)^{26}$ and lower than that of Senegal $(72.6 \%) .{ }^{6}$ This variation might be due to the difference in study populations' socio-demographic and economic characteristics as 


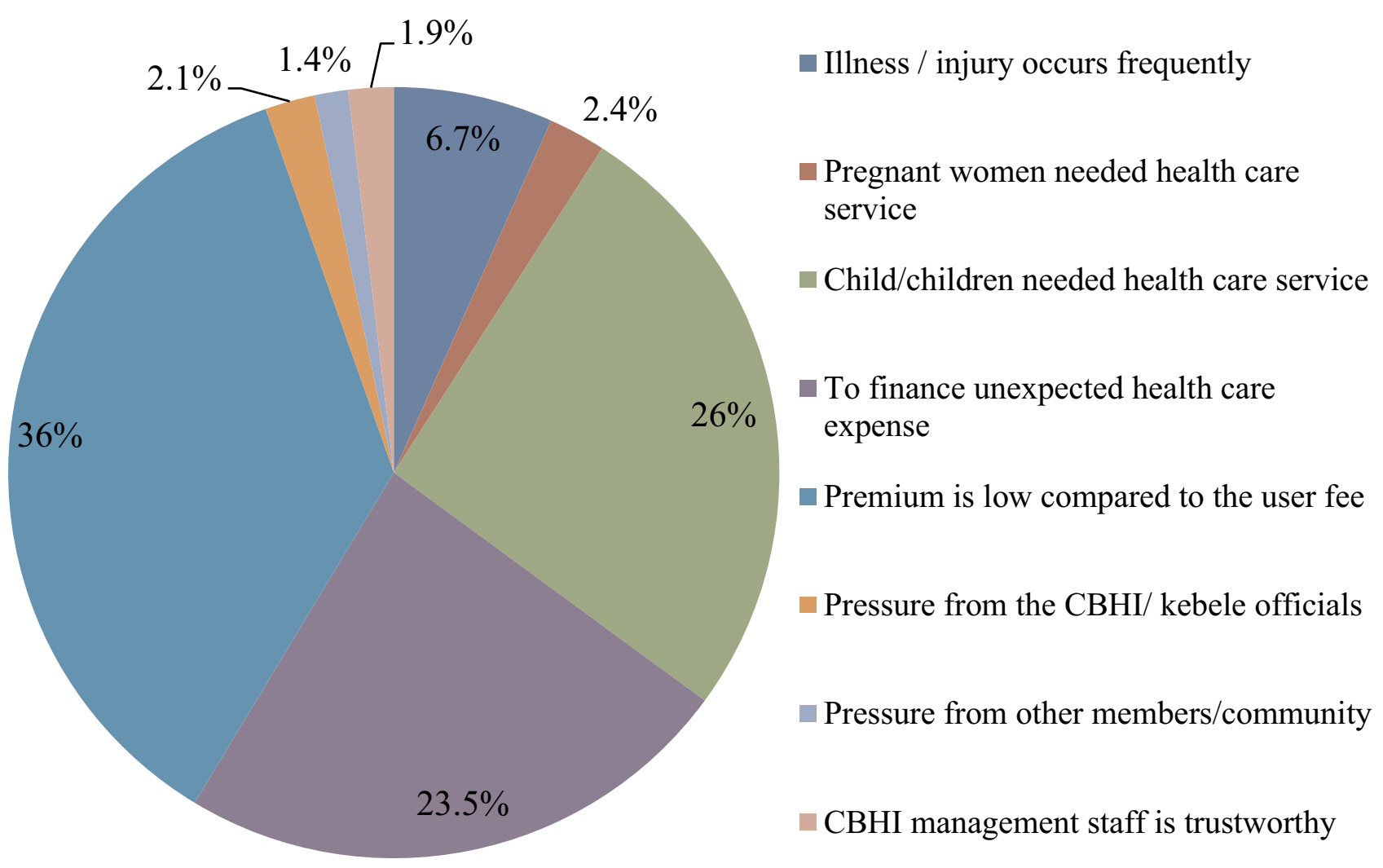

Figure 5 Best single reasons for renewing of $\mathrm{CBHI}$ membership among household in Manna district, Jimma zone, Oromia Regional State, Southwest, Ethiopia, 2020 ( $\mathrm{n}=420$ ).

well as the study period. In addition, the healthcare systems of these countries vary based on their particular health policy.

This study showed that household heads falling in age group above 50 years were less likely to dropout from CBHI as compared to household heads falling in the age group of their 20s. This finding was supported by a study conducted in Vietnam, ${ }^{26}$ but there was no significant difference detected in terms of the age between the two CBHI status in Burkina Faso. ${ }^{24}$ This could be due to the fact that older age individuals have relatively less immunity and are more likely prone to sickness than younger individuals. Moreover, older household heads might have higher life experiences and therefore are more likely to imagine the effect of illness or injury on their household.

This study also revealed that household head's educational level was also one of the significant determinants of dropout from CBHI. Accordingly, households whose educational level was primary, secondary, and above were likely to drop from $\mathrm{CBHI}$ as compared to those who were illiterate, unable to read and write. This finding was also supported by study findings in Sudan and Bangladesh. ${ }^{27,28}$ The possible explanation might be more educated people most probably have understanding of the benefits packages, working principles, and mechanisms of risk sharing in health insurance, hence less likely to dropout. In addition, educated people are more open to new concepts like healthcare reforms and more aware of the uncertainty nature of health crises and its consequences, which increases their preference for risk aversion.

Another finding in this study was that households who had greater than five family members were less likely to dropout from CBHI as compared to those who had less than or equal to five family members. This finding was in line with study findings in rural India. ${ }^{29}$ This could be due to the fact that, as the family size increases, the frequency and probability of people getting ill might also increase, and out-of-pocket payment for seeking treatment may result in financial crisis. Moreover, in our cases, as long as the age of the children is less than 18 , the insurance premium is the same for a family with one child and one with many children. Therefore, households who had larger family sizes may be less likely to dropout from the scheme. However, larger family size increases the odds of dropout from CBHI according to a study conducted in Burkina Faso. The possible explanation could 
Table 2 Predictors of Dropout from CBHI Among Households in Manna District, Jimma Zone, Oromia Regional State, Southwest Ethiopia, 2020

\begin{tabular}{|c|c|c|c|c|}
\hline \multirow[t]{2}{*}{ Variables } & \multicolumn{2}{|c|}{ CBHI Status } & \multirow{2}{*}{ COR $(95 \% \mathrm{CI})$} & \multirow[t]{2}{*}{ AOR $(95 \% \mathrm{Cl})$} \\
\hline & $\begin{array}{l}\text { Renewed, } \\
\text { N (\%) }\end{array}$ & $\begin{array}{l}\text { Dropped, } \\
\text { N (\%) }\end{array}$ & & \\
\hline \multicolumn{5}{|l|}{ Household heads' age in years } \\
\hline $18-30$ & $37(8.8)$ & $25(12.7)$ & Ref & \\
\hline $31-40$ & $|3|(3 \mid .2)$ & $74(37.6)$ & $0.84(0.47-1.49)$ & $0.61(0.24-1.56)$ \\
\hline $40-50$ & $133(3 \mid .7)$ & $64(32.5)$ & $0.7 \mid(0.39-1.28)$ & $0.55(0.20-1.47)$ \\
\hline$\geq 5$ I & $119(28.3)$ & $34(17.3)$ & $0.42(0.22-0.79)$ & $0.26(0.10-0.78) *$ \\
\hline \multicolumn{5}{|l|}{ Household heads' sex } \\
\hline Male & $370(88.1)$ & $152(77.2)$ & Ref & \\
\hline Female & $50(11.9)$ & $49(22.8)$ & $2.19(1.40-3.40)$ & $1.60(0.75-3.30)$ \\
\hline \multicolumn{5}{|c|}{ Household heads' educational level } \\
\hline Unable to read and write & $105(25.0)$ & $94(47.7)$ & Ref & \\
\hline Able to read and write & $74(17.6)$ & $40(20.3)$ & $0.60(0.38-0.97)$ & $0.64(0.28-1.50)$ \\
\hline Primary education & $135(32.1)$ & $46(23.4)$ & $0.38(0.25-0.59)$ & $0.32(0.16-0.66) *$ \\
\hline Secondary and above & $106(25.2)$ & $17(8.6)$ & $0.18(0.1-0.32)$ & $0.16(0.10-0.41)^{* *}$ \\
\hline \multicolumn{5}{|l|}{ Households family size } \\
\hline$\leq 5$ & $175(4 \mid .7)$ & $126(64.0)$ & Ref & \\
\hline$>5$ & $245(58.3)$ & $71(36.0)$ & $0.40(0.28-0.57)$ & $0.36(0.19-0.66) * *$ \\
\hline \multicolumn{5}{|c|}{ Distance from the nearest health facility (in minutes) } \\
\hline$<30$ & $134(32.6)$ & $48(24.4)$ & Ref & \\
\hline$\geq 30$ & $283(67.4)$ & $149(75.6)$ & $1.50(1.00-2.20)$ & $0.99(0.49-1.99)$ \\
\hline \multicolumn{5}{|l|}{ Understanding of $\mathrm{CBHI}$} \\
\hline Low level & $97(23.1)$ & $81(4 I .1)$ & Ref & \\
\hline High level & $323(76.9)$ & $116(58.9)$ & $0.086(0.03-0.2)$ & $0.57(0.32-1.03)$ \\
\hline \multicolumn{5}{|l|}{ Attitude towards $\mathrm{CBHI}$} \\
\hline Unfavorable & $27(6.4)$ & $35(17.8)$ & $3.26(1.9-5.6)$ & $\mathrm{I} .43(0.37-5.57)$ \\
\hline Neutral & $8(1.9)$ & $9(4.6)$ & $2.83(1.1-7.5)$ & $0.44(0.17-1.15)$ \\
\hline Favorable & $386(91.7)$ & 153 (77.7) & Ref & \\
\hline \multicolumn{5}{|l|}{ Capacity to afford } \\
\hline Low level & $65(15.5)$ & $105(53.3)$ & Ref & \\
\hline Medium level & $22(5.2)$ & $26(13.2)$ & $0.22(0.14-0.34)$ & $0.61(0.29-1.31)$ \\
\hline High level & $333(79.3)$ & $66(33.5)$ & $0.19(0.13-0.3)$ & $0.68(0.31-1.47)$ \\
\hline \multicolumn{5}{|l|}{ Perceived quality of service } \\
\hline Poor & $44(10.5)$ & $120(60.9)$ & $21.5(13.1-35)$ & $5.7(2.8-11.8) * *$ \\
\hline Medium & $108(25.7)$ & $43(21.8)$ & $3.1(1.9-5.2)$ & $1.3(0.67-2.69)$ \\
\hline Good & $268(63.8)$ & $34(17.3)$ & Ref & \\
\hline \multicolumn{5}{|c|}{ Received promised Benefit package } \\
\hline Disagree & $50(11.9)$ & $100(50.8)$ & II.7 (7.4-18.5) & $4.9(2.4-9.9) * *$ \\
\hline Neutral & $83(19.8)$ & $48(24.4)$ & $3.39(1.1-5.4)$ & $2.8(1.4-5.8) *$ \\
\hline Agree & $287(68.3)$ & $49(24.9)$ & Ref & \\
\hline \multicolumn{5}{|l|}{ Provider's attitude } \\
\hline Unfavorable & $67(16.0)$ & $|4|(7 \mid .5)$ & $48(22.5-104)$ & $10(4.0-25.4) * *$ \\
\hline Neutral & $169(40.2)$ & $48(24.4)$ & $6.5(3.0-14.2)$ & $4.0(1.5-9.99) *$ \\
\hline Favorable & $184(43.8)$ & $8(4.1)$ & Ref & \\
\hline
\end{tabular}

(Continued) 
Table 2 (Continued).

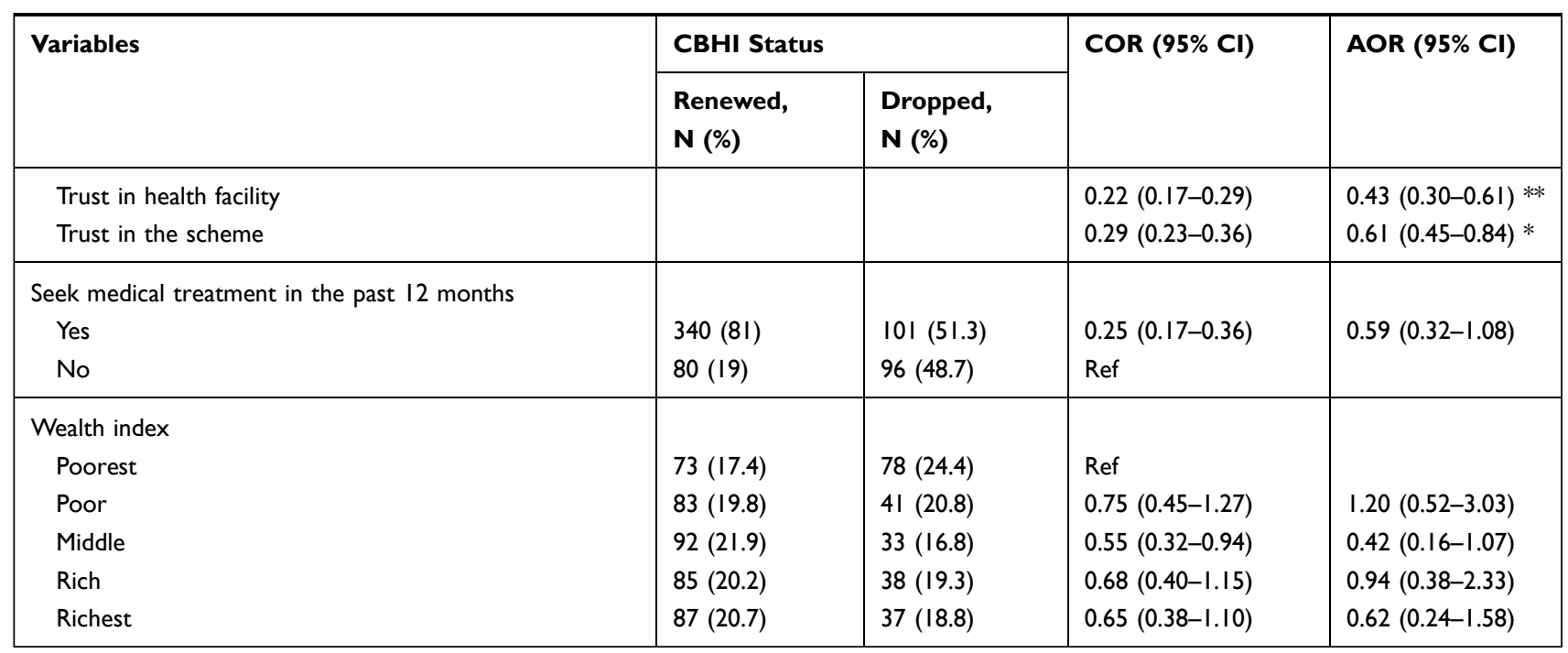

Note: **and *Denote statistical significance at the $1 \%$ and $5 \%$ level, respectively. Abbreviation: Ref, reference group.

be in Burkina Faso households were expected to add 3 US \$ per individual of 15 years and older; and 2 US\$ per individual less than 15 years of age on the annual premium, which might increase the dropout from $\mathrm{CBHI}{ }^{24}$

This study illustrated that poor perceived quality of service significantly increased the odds of dropout by almost 6-fold as compared to good perceived quality. This finding was similar with studies conducted in Senegal and Burkina Faso which indicated that poor perceived quality of service provided for members was the main determinant of dropout from CBHI. ${ }^{6,24}$ This could be due to the gap between what the members expect and experience when they visit health facilities. When their prior expectation fails to match with what they actually experience at the health facilities their probability of satisfaction could be low. This finding implies that provision of good quality services is a prerequisite for the success of the CBHI scheme since service quality influences patients' perceived value, their satisfaction, and faithfulness.

Trust in contracted health facilities had a strong association with dropout from CBHI. Accordingly, for each one unit increase in the trust score of the public healthcare facilities, the odds dropout from CBHI was decreased by more than half. This finding was in accordance with study findings conducted in Cambodia and Ethiopia. ${ }^{30,31}$ These could be further explained by failure to respond to consumer's demand and client affairs might impose a lack of trust in health facilities which results in dropout from the scheme. However, increasing availability and accessibility of the service without compromising the quality irrespective of any criteria to fulfill the members' expectation will enhance the trust of member in the health facility so that they prefer staying being a member of $\mathrm{CBHI}$ by renewing their membership.

Furthermore, for each one unit increase of trust score in the CBHI scheme, the odds of dropout from CBHI decrease by $39 \%$. This evidence is also supported by a study conducted in Ethiopia, which indicates for each one unit increase in the trust score of the CBHI scheme, the odds of willingness to renew CBHI membership was increased by $40 \%{ }^{31}$ This could be because the scheme is reliable, has concern and commitment to fulfill the interest of the member, their confidence may increase and more rely on the scheme, which in turn increase the retention of the members.

This study demonstrated that provider's attitude towards CBHI members has a greater influence to retain membership. Accordingly, unfavorable and neutral provider's attitudes towards CBHI members increased the odds of dropout as compared to favorable provider's attitudes. This evidence was supported by a study conducted in Ghana. ${ }^{32}$ A study in Benin also reported that $30 \%$ of members left a scheme because of providers' negative behaviors, which indicate that perceived poor providers' attitude had a relationship with dropout from CBHI. ${ }^{33}$ This could be if members do not get equal service with equal respect as that of fee payers; members risk minimization through insurance is low. This also could be dissatisfaction 
with provider rudeness, preference given to cash-paying uninsured patients, and differential treatment depending on patients' socio-economic status for which they prefer not to renew their membership and find other health risk coping mechanisms.

Regarding the benefit package of CBHI, this study illustrated that those who disagree and are the neutral with received promised package had higher odds of dropout from the scheme as compared to those who agree with the received promised benefit package. This finding was in line with studies in Benin and Uganda, which showed that a lack of satisfaction with the insurance benefits package was reported to be a major factor that affects dropout from the CBHI scheme. ${ }^{33-35}$ In addition, this evidence was supported by a study in Ghana and meta-analysis conducted in LAMIC which indicated that provision of a limited promised benefits package was one of the determinants of dropout from the CBHI scheme. ${ }^{25,36}$ This could be further explained by when individuals go to health institutions; they expect to get all services which were promised to them before they were enrolled in the scheme except a few services are excluded from the benefit package. When they lose the promised benefit package they might decide not to be a member anymore and quit their membership.

The study is expected to provide insight and useful information for the existing $\mathrm{CBHI}$ scheme in Ethiopia and other LAMIC. However, the study might be prone to social desirability bias as individuals might respond to the question in a way that is acceptable to many, other than expressing their feelings, and recall bias, as study participants were asked about the past 12 month illness history and health service utilization related to the $\mathrm{CBHI}$.

\section{Conclusion}

The finding of the study showed that dropout from CBHI in the Manna district was found to be high compared to other study reports and poor perceived quality of the health service, failure to provide the promised benefit package and perceived negative attitude of providers' toward $\mathrm{CBHI}$ members were the significant contributing determinants of high dropout, whereas members with greater family size, relatively older age and educated household were less likely to dropout and both trust in contracted health facility and the scheme had a negative relationship with dropout from the $\mathrm{CBHI}$ scheme.

We strongly recommend that the district health office and public health facilities in the district should give more emphasis on providing the promised benefit package, work on improving the quality of health services, and the attitude of healthcare providers toward members of the scheme. The district CBHI scheme also should reimburse the payment to the health facilities timely and pay attention to the socio-demographic and economic characteristics of its members. The health facility and CBHI scheme were recommended to be reliable and concerned on the need of members in provision of services in order that increase member's confidence which in turn increase trust of member on a health facility as well as on CBHI scheme to facilitate retention of $\mathrm{CBHI}$ members.

\section{Acknowledgment}

Our special thanks go to Jimma University, Manna district Health office and community for their support of this study.

\section{Disclosure}

The authors received no financial support to be disclosed and the authors report no conflicts of interest.

\section{References}

1. Lanthaume P. ILO. Social protection platform theme: community based health insurance/health microinsurance premiums [Internet]; 2012. Available from: https://www.social-protection.org. Accessed Jan 6, 2020.

2. Mcintyre D, Kutzin J. Health Financing Guidance: Health Financing Country Diagnostic: A Foundation for National Strategy Development. Geneva, Swezerland: WHO; 2016.

3. Carrin G. Community Based Health Insurance Schemes in Developing Countries: Facts, Problems and Perspectives. Geneva, Swezerland: WHO; 2003.

4. WHO. Fifty-Eight World Assembly. Resolution and Decision. Geneva: Palais des Nations; 2005.

5. Panda P, Chakraborty A, Raza W, Arjun S. Renewing membership in three community- based health insurance schemes in rural India. Health Policy Plan. 2016;31(10):1433-1444. doi:10.1093/heapol/ czw090

6. Mladovsky P. Why do people drop out of community- based health insurance?: findings from an exploratory household survey in Senegal. Soc Sci Med. 2015;78-88.

7. Savitha B. Why members dropout? An evaluation of factors affecting renewal in micro health insurance in India. J Health Manag. 2017;19:2. doi:10.1177/0972063417699691

8. De Allegri M, Sauerborn R, Kouyaté B, Flessa S. Community health insurance in sub-Saharan Africa: what operational difficulties hamper its successful development? Trop Med Int Heal. 2009;14(5):586-596. doi:10.1111/j.1365-3156.2009.02262.x

9. Muchabaiwa L, et al. Feasibility and sustainability of community based health insurance in rural areas: case study of Musana, Zimbabwe. Expert J Financ. 2017;5:73-85.

10. Umeh $C$. Challenges toward achieving universal health coverage in Ghana, Kenya, Nigeria, and Tanzania. Wiley. 2018;33(4):794-805.

11. UNCTAD. The Least Developed Countries Report: Entrepreneurship for Structural Transformation: Beyond Business as Usual. New York, USA; 2017. 
12. Radzewicz-Bak B, Hellwig K-P, Ruiz SL, Tavares MM, And AP, Ramirez G. FDRE: IMF report on selected issue: equitable growth and poverty reduction in Ethiopia.International household survey network. 2015.

13. FMOH. Ethiopia's Seventh National Health Account 2016/2017. Addis Ababa, Ethiopia; 2019.

14. Xu K, Evans DB, Guido C, Aguilar-Rivera AM, Musgrove P, Evans T. Protecting households from catastrophic health spending. Health Aff. 2007;26:4. doi:10.1377/hlthaff.26.4.972

15. Ayenew Haileselassie, Rockville HB and GG. Ethiopia Health Sector Finance Reform/Health Finance and Governance Project: End-OfProject report: Health Finance and Governance Project: Abt Associates; 2018.

16. EHIA. Evaluation of Community Based Health Insurance on Pilot Schemes in Ethiopia Final Report. Addis Ababa, Ethiopia; 2015.

17. Alebachew A, Yusuf Y, Mann C, Berman P. Ethiopia's Progress in health financing and the contribution of the 1998 Health Care and financing Strategy in Ethiopia. Breakthrough International Consultancy PLC. 2015.

18. Johns B, Mignote Haile ZA. Health sector finance reform/health finance and governance (HSFR/HFG) Project: CBHI in Ethiopia assessing institutional and financial sustainability. Abt Associates Inc. 2018.

19. FMOH. Health sector transformational plan I: Annual performance report. Ethiopian Federal Ministry of Health Fiscal Year Report. version. 2017;1.

20. Mebratie AD, Sparrow R, Yilma Z, Alemu G, Bedi AS. Dropping out of Ethiopia's community-based health insurance scheme. Health Policy Plan. 2015;30(10):1296-1306. doi:10.1093/heapol/czu142

21. Mukangendo M, Nzayirambaho M, Hitimana R, Yamuragiye A. Factors contributing to low adherence to community based health insurance in rural nyanza district, southern Rwanda. Environ Public Heal. 2018;1-10.

22. Kothari CR. Research methodology: methods and technique in university of Rajasthan: new age international publisher. 2004. Second Rev. 1-412. new delhi, India.

23. Kutzin J, Witter S, Jowett M, Bayarsaikhan D. Developing a national health financing strategy: a reference guide: health financing guidance series by WHO. Creative Commons Attribution. 2017.

24. Dong H, De AM, Gnawali D, Souares A, Sauerborn R. Drop-out analysis of community-based health insurance membership at Nouna, Burkina Faso. Elsevier. 2009;92(2-3):174-179.
25. Atinga RA, Abiiro GA, Kuganab-lem RB. Factors influencing the decision to drop out of health insurance enrolment among urban slum dwellers in Ghana. Trop Med Int Heal. 2015;20(3):312-321. doi: $10.1111 /$ tmi. 12433

26. Van M, Anh T, Thuy N. Health insurance drop-out among adult population: findings from a study in a Health and demographic surveillance system in Northern Vietnam 2006-2013. Glob Heal Epidemiol Genomics. 2016;1:10-14.

27. Herberholz C. Determinants of voluntary national health insurance drop-out in Eastern Sudan. Appl Health Econ Health Policy. 2016;15:2.

28. Iqbal M, Chowdhury A, Mahmood S. Socioeconomic and programmatic determinants of renewal of membership in a voluntary micro health insurance scheme: evidence from Chakaria. Glob Health Action. 2017:10(1). doi:10.1080/16549716.2017.1287398.

29. Panda WR. Analyses of enrolment, dropout and effectiveness of RSBY in northern rural India. MPRA. 2016;(70081).

30. Ozawa S, Walker D. Trust in the context of community based health insurance schemes in Cambodia: villagers' trust in health insurer. Emerald Gr Publ Ltd. 2009;21:107-132.

31. Asmamawu A. Community based health insurance in Ethiopia: enrollment, membership renewal, and effects on health service utilization. Creative Commons. 2018.

32. Awudu S. National health insurance scheme: predictors of card renewal among subscribers in the East Gonja district of Ghana. University of Ghana Digital collections. 2016.

33. Turcotte T, et al. Mapping of initiatives to increase membership in mutual health organizations in Benin. Int J Equity Health. 2012;11 (1):1-15.

34. Basaza R, Criel B, Stuyft PVD. Low enrolment in Ugandan community health Insurance schemes: underlying causes and policy implications. BioMed Cent. 2007;12(1).

35. Kyomugisha EL, Buregyeya E, Ekirapa E, Mugisha JF, Bazeyo W. Strategies for sustainability and equity of prepayment health schemes in Uganda. Afr Health Sci. 2009;9(2):59-65.

36. Dror D, Hossain S, Majumdar A, Pérez T, John D, Panda P. What factors affect voluntary uptake of community based health insurance schemes in low and middle income Countries? A systematic review and meta-analysis. PLoS One. 2016;11(8):1-31. doi:10.1371/journal. pone. 0160479
ClinicoEconomics and Outcomes Research

\section{Publish your work in this journal}

ClinicoEconomics and Outcomes Research is an international, peerreviewed open-access journal focusing on Health Technology Assessment, Pharmacoeconomics and Outcomes Research in the areas of diagnosis, medical devices, and clinical, surgical and pharmacological intervention. The economic impact of health policy and health systems organization also constitute important areas of coverage. The manuscript management system is completely online and includes a very quick and fair peer-review system, which is all easy to use. Visit http://www.dovepress.com/testimonials.php to read real quotes from published authors. 